\title{
Entre los «cuentos chinos» y la realidad ${ }^{1}$
}

(El surgimiento de China: un dilema central de la política exterior argentina)

\section{LA Argentina AISLADA}

La Argentina se encuentra aislada del mundo y su reputación internacional ha declinado mucho en los últimos tiempos. El próximo gobierno que asuma en el 2015 deberá realizar profundas modificaciones para corregir los desaciertos de los últimos años.

Toda política exterior es vulnerable a los efectos de una crisis interna de gran envergadura como la que vivió la Argentina entre los años 2001 y 2003. Las repercusiones internacionales más gravosas de la crisis fueron el quebranto del crédito público y el profundo deterioro en la relación con las principales naciones europeas, que vieron malogradas sus inversiones en el país. ${ }^{2}$

La política exterior de los últimos diez años no supo subsanar estos severos reveses. Tampoco fue capaz de crear un clima de renovada confianza con los Estados Unidos, ni supo articular con Brasil una política que destrabe el ya perenne estancamiento del Mercosur.

Conferencia privada en la Academia de Ciencias Morales y Políticas, Buenos Aires, (noviembre 2013).

2 Quien quiera indagar en detalle las consecuencias de la crisis 2001/2003 sobre la política exterior puede consultar el artículo que publiqué en la revista Agenda Internacional (noviembre, 2009) sobre: «La política exterior de los gobiernos Kirchner». 
Después de 10 años, el país sigue en «default» sin recuperar el acceso a los mercados voluntarios de deuda, lo que encarece la inversión de largo plazo tanto pública como privada.

Los niveles de endeudamiento se redujeron sustancialmente gracias a la renegociación de la deuda instrumentada en el $2005 / 2010$. Pero la prima de riesgo país (el costo de endeudarse) -que es la verdadera medida del acceso al crédito- se mantuvo en niveles altísimos: tres veces más altos que los de Brasil, Chile o México.

Las recientes iniciativas del gobierno para restablecer el crédito argentino llegan tarde y son fruto de una creciente debilidad en materia fiscal y de un disminuido nivel de reservas en el Banco Central.

De todas formas, renegociar las deudas impagas con los bancos de exportación (el Club de Paris), satisfacer los requerimientos del FMI de que se publiquen estadísticas confiables, aceptar responsabilidades en materia de juicios perdidos en el CIADI y postergar hasta el 2015 las decisiones de la justicia norteamericana respecto a los bonistas impagos (los «holdouts»), son señales en el proceso de volver a integrarse al mundo.

En materia de comercio internacional, a pesar de las favorables circunstancias internacionales, no hemos diversificado el patrón de exportaciones. Del lado de las importaciones, las restricciones discrecionales aplicadas por la Secretaria de Comercio suscitaron numerosas acciones legales en contra de nuestro país ante la Organización Mundial del Comercio (OMC).

Además, perdimos mercados importantes. Pasamos de ser el tercer exportador mundial de carnes a exportar menos que el Uruguay. En el 2010, perdimos el acceso al «sistema de preferencias generalizadas» en el mercado norteamericano que favorecía a nuestras exportaciones regionales. Ahora, después de transformarnos en líder mundial en la exportación de biodiesel, los europeos nos han cerrado su mercado.

En materia de inversión extranjera directa, la recurrente inestabilidad y discrecionalidad en la aplicación de las reglas del juego redujo dramáticamente el flujo de nuevas inversiones. En el año 2012, Argentina recibió nuevas inversiones extranjeras directas (sin tomar en cuenta la reinversión de utilidades) por solo US\$ 4.000 millones, mientras que Brasil recibió por US\$ 65.000 millones y Chile por US\$ 30.000. 
El estilo de conducción que el gobierno practica en la política interna se proyectó al escenario internacional con una agenda reactiva y poco respetuosa de las formas diplomáticas establecidas.

No creo que la diplomacia norteamericana haya olvidado el escándalo que ocurrió en Mar del Plata durante la reunión hemisférica, cuando se discutió el futuro del ALCA. Tampoco creo que olviden la escena de nuestro canciller abordando un avión militar norteamericano para confiscar equipos de comunicaciones y claves secretas.

Tampoco creo que los uruguayos hayan olvidado el prolongado bloqueo al principal puente internacional entre nuestros dos países, ni los chilenos el anuncio intempestivo de los recortes de gas natural a Chile durante el invierno del año 2005.

La politiquería y el amiguismo invadieron el aparato burocrático de la Cancillería. Se desplazó o eliminó a experimentados funcionarios de carrera, nombrando en puestos claves a militantes sin experiencia.

El Instituto del Servicio Exterior de la Nación, uno de los pocos centros de entrenamiento de excelencia creado por el Estado durante los últimos cincuenta años, sufre hoy un grave deterioro en su plantel de profesores y en la calidad del entrenamiento que imparte.

Al Gobierno le cuesta interpretar las nuevas tendencias internacionales y no sabe aprovechar las oportunidades que ofrece el escenario para mejorar la situación de nuestro país en el mundo.

En lo internacional, el país está cada día más aislado y no tiene una estrategia clara y articulada -mucho menos consensuada- en materia de alianzas, relaciones económicas preferenciales y tácticas diplomáticas.

\section{El ascenso de China y SUS CONSECUENCiAS EN EL ESCENARIO MUNDIAL}

El proceso de globalización que se inició después de la Segunda Guerra Mundial, se extendió vigorosamente durante los últimos 25 años a China, a los ex miembros del bloque 
soviético y al mundo de los países emergentes en Asia, África y América Latina.

Las reformas pro-mercado introducidas por China, en conjunción con una altísima tasa de inversión, generaron un formidable avance económico durante las últimas décadas. En la actualidad la economía china es la segunda más grande del mundo en términos de PBI y la primera en términos de producción industrial. Su participación en las exportaciones mundiales se incrementó del $2 \%$ en 1990 al 4\% en el 2000 y al $11 \%$ en la actualidad. China ocupa el tercer lugar (después de los Estados Unidos y Japón) en términos de inversión extranjera directa y es el primer tenedor de reservas internacionales (US\$ 3.600.000 millones, al 31 de octubre de 2013).

China continuará creciendo en los próximos años, pero a tasas menores que en el pasado. Su modelo de crecimiento «a todo vapor» ha generado consecuencias indeseadas. El crecimiento es excesivamente dependiente de la inversión fija y de las exportaciones (en detrimento del consumo) y existen graves ineficiencias en el sector bancario y en el funcionamiento de las grandes empresas públicas.

Los Estados Unidos y China serán durante las próximas décadas las principales potencias mundiales tanto en el campo económico como en el político y militar.

En los centros de poder mundial, el ascenso de China desata temores respecto del futuro equilibrio mundial, ya que constituye una amenaza a la preeminencia de los Estados Unidos y pone en jaque los arreglos «de jure y de facto" que le dan sustento al sistema internacional creado después de la Segunda Guerra Mundial.

Recordemos, en este sentido, la reacción de Esparta ante el fortalecimiento de Atenas - tan lucidamente descripta por Tucídides en «Las Guerras del Peloponeso» - y más recientemente las consecuencias del surgimiento de Alemania, Japón y la Unión Soviética durante el tumultuoso siglo XX.

Hasta ahora, China aceptó el «statu quo» internacional y jugó un rol constructivo y responsable en el escenario mundial. China se incorporó gradualmente al sistema de normas, reglas e instituciones que le dieron sustento a la llamada "pax americana». 
Se asoció como miembro activo a las principales instituciones económicas multilaterales, como el FMI, el Banco Mundial y la OMC. Participó en el diálogo sobre el control de armas de destrucción masiva y cooperó con las potencias occidentales en el combate contra el terrorismo.

También aumentó su participación en el sistema de las Naciones Unidas, en el Consejo de Seguridad y participó en numerosas Operaciones de Paz. Durante la década de 1990, se incorporó en forma activa a más de diez organizaciones regionales, entre ellas la Asociación de Países del Sudeste Asiático (ASEAN) y la Organización de Cooperación de Shanghái (que incorpora a Rusia y a las Repúblicas de Asia Central en proyectos de cooperación económica, energética y de defensa).

Entre China y los Estados Unidos predominó hasta ahora una intensa interdependencia económica sobre las potenciales diferencias que existen en el campo de la geopolítica y la ideología.

Estados Unidos le ofrece un gran mercado a las exportaciones chinas y las multinacionales norteamericanas son grandes inversoras en dicho país. China tiene en Washington un formidable lobby de empresas locales que morigeran las presiones proteccionistas que podrían poner en peligro la simbiosis de intereses que sustenta la relación actual.

China provee muchos de los bienes que permitieron la extraordinaria bonanza del consumidor norteamericano durante las últimas décadas. Además, es el principal financista de Washington a través de la compra de títulos públicos, lo que contribuye a mantener bajas las tasas de interés y a estimular la actividad económica.

A pesar de lo expuesto, la relación bilateral entre los Estados Unidos y China tiene aristas conflictivas en el campo de la geopolítica y lo ideológico.

En el campo de la geopolítica, China se opuso a las intervenciones de los Estados Unidos y sus aliados occidentales en Irak, Libia y más recientemente en Siria. Apoya al régimen de Corea del Norte y ha desarrollado una relación económica y política privilegiada con Irán.

Además, tiene una larga lista de contenciosos con numerosos vecinos. Sin duda el más serio es el de Taiwán, considerado por China como una provincia rebelde. Durante los últimos 
años, el control sobre el Mar de China y el Mar Amarillo (donde existen importantes recursos de petróleo y gas natural «offshore») ha suscitado graves tensiones y roces con el Japón, Corea del Sur, Filipinas y Vietnam y crea un temor difuso a una posible desestabilización regional.

China no tiene aún los medios militares para disputar a los Estados Unidos su primacía, pero su gasto en materia de defensa y equipamiento militar está aumentando rápidamente.

La marina de guerra ya posee más submarinos que la rusa y espera convertirse en una armada bioceánica para fines de esta década. Su estrategia naval se complementa con un ambicioso esfuerzo en materia de satélites, misiles de mediano y largo alcance y capacidad de guerra cibernética. Este hecho preocupa a Washington a tal punto que hace pocos meses anunció el gradual traslado de importantes fuerzas navales y aéreas hacia esa región.

La alianza militar de los Estados Unidos con Japón, Corea del Sur, Australia y Filipinas es vista con suspicacia por los medios dirigentes de Pekín. Sospechan que el escudo misilístico que Estados Unidos desarrolla con Japón sea en su contra y no una respuesta al desarrollo nuclear y misilístico de Corea del Norte como se anuncia.

En el campo ideológico, también existen profundas diferencias. Los aliados occidentales promueven un sistema político democrático/liberal que es antagónico con el sistema de partido único que gobierna China.

La dirigencia china privilegia el predominio del Estado sobre la sociedad. China sigue siendo un país autoritario, sin elecciones libres, con severas restricciones a la libertad de prensa y al uso del internet. Las demandas de democratización son postergadas y, en algunos casos, reprimidas con severidad.

La expectativa de que el régimen chino podría lentamente girar hacia un sistema democrático/liberal tiene, por ahora, poco asidero en la realidad. La primacía del partido único es consistente con muchos valores de su cultura y con la tradición política imperial.

El crecimiento económico redujo dramáticamente la pobreza y modernizó la sociedad. Pero las desigualdades sociales, la corrupción institucional y graves problemas de deterioro ambiental se multiplicaron durante los últimos años. 
Por ahora, la población privilegia el progreso económico y el reconocimiento que el país está recibiendo en el escenario mundial sobre cualquier otra consideración política. Los recuerdos de un pasado reciente de pobreza extrema y convulsiones políticas, sirve de antídoto al espíritu de protesta.

Pero en un mundo donde la información se ha vuelto porosa, la conjunción de los problemas ya mencionados más el autoritarismo, genera resentimientos en la población, que están siendo canalizados por el Partido Comunista a través de un descarnado nacionalismo.

La profundización de estos problemas y la ocurrencia de una crisis económica podrían generar desequilibrios que amenacen la estabilidad del sistema. El surgimiento de tensiones podría dificultar el margen de maniobra del régimen en el campo internacional. También podría llevarlo a tentarse con aventuras externas para compensar sus dificultades internas.

Los Estados Unidos nunca han aceptado que una potencia competitiva ejerza una hegemonía exclusiva sobre el continente asiático o europeo. Las dos guerras mundiales del siglo XX y la Guerra Fría son la clara muestra de esto.

La transformación de China en una potencia hegemónica regional desequilibrará el balance de poder militar en Asia con consecuencias importantes para los Estados Unidos y Japón. Cuando esto ocurra, las tensiones crecientes podrían desembocar en un conflicto militar localizado y/o una disputa a través de terceros Estados, o directamente en un conflicto militar entre las dos grandes potencias.

Nuestra política exterior necesita incorporar en su hoja de cálculo las posibles consecuencias y ramificaciones económicas, políticas y militares de este complejo escenario.

\section{LA ARgentinA: ENTRE LOS «CUENTOS CHINOS»Y}

\section{LA REALIDAD}

Históricamente, las relaciones entre la Argentina y China fueron poco significativas en razón de pertenecer geográfica y culturalmente a regiones distantes y muy diferentes. Las relaciones diplomáticas se restablecieron en 1972. Durante los últimos 20 años, las relaciones se ampliaron en todos los 
campos: no solo en lo político y comercial sino también en el cultural, científico y militar.

China apoya la posición argentina sobre las Malvinas y nuestro país a cambio aceptó la posición de Pekín respecto de Taiwán. Los dos países han cooperado provechosamente en diversos foros multilaterales, como en las negociaciones de la Ronda Doha (en la OMC), sobre el cambio climático y el Grupo de los Veinte (G20).

La irrupción de China en el escenario mundial es beneficiosa para nuestro país si sabemos entenderla y aprovecharla. Desafortunadamente, el surgimiento de China ha generado en numerosas comentaristas locales (gobierno, academia y periodismo) exageraciones respecto de la importancia futura de la relación bilateral, que no coinciden con la realidad.

La economía argentina y la china, en el campo comercial, son mucho menos complementarias que lo que se repite hasta el hartazgo en la prensa y en artículos pseudo académicos que no han analizado en detalle las estructuras productivas de ambos países.

Investigaciones realizadas por Fiel para determinar la complementariedad entre las dos economías -tanto en lo agroalimentario como en las manufacturas- sugieren cautela. El índice de Michaely -utilizado para determinar la complementariedad de los patrones comerciales que tienen las dos economías- muestra un bajo grado de coincidencia entre las exportaciones argentinas y las importaciones chinas en comparación con un centenar de mercados alternativos. ${ }^{3}$

Si bien la relación con China es relevante, no se compara ni cuantitativamente ni cualitativamente con la densa interdependencia que mantuvimos con Gran Bretaña en el siglo pasado.

Nuestras exportaciones promedio a Gran Bretaña entre 1870 y 1940 representaron alrededor del 35\% de nuestras exportaciones totales (versus $7,5 \%$ en el caso de China) y el stock de la inversión directa británico representaba casi el $40 \%$ de la inversión extranjera directa total en el país (menos del $10 \%$ en el caso de China).

M. Cristini y G. Bermúdez: «Documento de trabajo N81: La nueva China cambia al mundo", Buenos Aires, septiembre 2004, Fiel. 
Dos razones explican esta profunda disparidad. Por un lado, la gran distancia geográfica encarece los costos de transporte y nos descoloca respecto a competidores como Australia, Nueva Zelandia, Estados Unidos y los países del sudeste asiático exportadores de materias primas.

Por otro lado, la complementariedad entre nuestras dos economías es limitada porque China (al revés de Gran Bretaña cien años atrás) es proteccionista en materia agropecuaria.

China es una gran productora de alimentos (produjo 560 millones de toneladas de granos en el 2012), aunque su producción nacional no alcanza para satisfacer todas sus necesidades.

La búsqueda de la autosuficiencia alimentaria es un objetivo permanente de todos los gobiernos chinos. Darle ingresos y empleo a casi 700 millones de chinos que viven en zonas rurales -donde además se concentran los mayores problemas de pobreza y desigualdad- es una prioridad política de primer rango.

El comercio bilateral entre la Argentina y China creció rápidamente durante los últimos quince años (de US\$ 900 millones en 1995 a casi US\$ 15.000 millones en el 2012).

El patrón de comercio bilateral actual es desequilibrado y la balanza comercial es deficitaria para la Argentina desde el año 2008, a pesar de las numerosas restricciones impuestas por la Secretaría de Comercio.

En la actualidad, China es nuestro tercer cliente comercial (7,5\% de nuestras exportaciones totales), después de Brasil $(20 \%)$ y la Unión Europea (17\%). La Argentina exporta un número limitado de materias primas. La soja y sus derivados concentran casi el 90\% de nuestras exportaciones, aproximadamente US\$ 5.500 millones. $^{4}$

El resto de las exportaciones argentinas al mercado chino son modestas y están representadas por unos cuarenta productos agropecuarios y agroindustriales. Durante el año 2012 se pueden mencionar en orden de importancia el tabaco (US\$103 millones), productos aviares (US\$ 80 millones), aceites de maní y girasol (US\$ 71 millones), lácteos (US\$ 60 millones), cebada (US\$ 40 millones), pescados (US\$ 28 millones), vinos

4 Desafortunadamente, las oleaginosas representan solo el $2 \%$ de las importaciones totales chinas. 
y uva (US\$ 26 millones), lana (US\$ 25 millones) y otros de menor cuantía.

Para tener un baño de realidad respecto de las oportunidades agro-exportadoras que nos ofrece el mercado chino sugiero consultar los excelentes trabajos realizados durante los últimos cinco años por la Consejería Agrícola en la Embajada Argentina en Pekín. ${ }^{5}$

Transformada en una formidable fábrica mundial de manufacturas, China le exportó a la Argentina casi US\$ 9.000 millones de productos industriales.

Importamos alrededor de cuatrocientos productos manufacturados de variado tenor, entre otros, computadoras y equipos electrónicos, radios, televisores y electrodomésticos, celulares, maquinaria eléctrica y de transporte, vehículos, motocicletas, glifosfato, juguetes, relojes, máquinas de coser, grifería, prendas de vestir y calzado.

China ingresa a nuestro mercado doméstico de manufacturas con pocas restricciones. Esto fue consecuencias de la firma por el gobierno de Néstor Kirchner de un «Memorándum de Entendimiento» (noviembre, 2004) por el cual Argentina reconoció a China como "economía de mercado" y renunció al uso de mecanismos de defensa comercial no autorizados por la OMC, exponiéndonos a represalias comerciales. ${ }^{6}$

Fue lo que sucedió en el 2010 cuando China frenó el ingreso de la soja por supuestos problemas de calidad, en respuesta a las restricciones discrecionales que la Secretaría de Comercio había impuesto al ingreso de ciertas manufacturas chinas (textiles, calzados y rodados). Después de arduas negociaciones y un significativo relajamiento de las restricciones argentinas, los chinos se avinieron a reabrir el mercado de la soja.

Los productos chinos compiten todavía poco con nuestras exportaciones de manufacturas, que están concentradas en América Latina, donde gozamos de preferencias arancelarias,

5 Ver en particular el DOC/CAP/011-2013: Análisis del Comercio Agrícola Chino en 2012, Omar Odarda, Consejería Agrícola, Embajada Argentina, Pekín, 31 de mayo de 2013.

6 Algunos expertos, inclusive el autor, criticaron dicha decisión por ser prematura y porque no se negoció, como mínimo, el acceso preferencial de alguno de nuestros productos, como por ejemplo la carne bovina o los lácteos, al mercado chino. 
arreglos de comercio administrado (la industria del automóvil) y de menores costos de comercialización y transporte.

Profundizar la integración con nuestros vecinos y practicar un proteccionismo regional moderado y bien administrado (a través de normas aprobadas por la OMC y no con medidas discrecionales) es imprescindible para sostener un desarrollo industrial razonable en nuestro país.

Por su parte, nuestros exportadores agroindustriales al mercado asiático ya compiten con los productos chinos. Nuestras exportaciones de harina de soja a China, que alcanzaron el millón de toneladas a fines de la década de 1990, fueron desplazadas por su producción doméstica a mediados de la década pasada.

Luego, China promovió sus exportaciones de harinas con un generoso régimen de reintegros y beneficios fiscales y crediticios. Esto le permitió competir, cabeza a cabeza, con las nuestras. Lo mismo está ocurriendo en la actualidad con la producción de aceite de soja.

El ascenso de China es provechoso para nuestro futuro más por sus consecuencias indirectas sobre la economía mundial (incremento en los precios de las materias primas y mejora en la performance económica de nuestros principales socios comerciales) que por sus efectos directos en nuestro perfil productivo.

China, a través de un «efecto locomotora», incrementa la demanda y mejora los precios internacionales de la soja que la Argentina exporta al mundo. (Contrario sensu a lo que se repite en la prensa, menos del $20 \%$ de nuestra producción de soja y derivados se vendió al mercado chino durante los últimos cinco años).

Asimismo, el crecimiento chino mejoró los precios de muchas materias primas (como el petróleo, el cobre, el mineral de hierro) lo que beneficia directamente la balanza comercial y la performance económica de varios de nuestros vecinos sudamericanos (en particular Brasil, Chile, Perú, Uruguay y Venezuela), que son importantes socios comerciales de Argentina.

Además, la vigorosa demanda asiática liderada por China mejora la performance económica de muchos países emergentes importadores de alimentos (principalmente en el Medio 
Oriente, Asia y África), lo que genera en la actualidad superávits en nuestra balanza comercial con dichas regiones y países.

El surgimiento chino también amplía nuestro margen de maniobra en las negociaciones comerciales internacionales. El proteccionismo agropecuario europeo y una relación comercial poco densa con los Estados Unidos limitaron, durante la segunda parte del siglo XX, las opciones argentinas en materia de inserción internacional.

Afortunadamente para nosotros, China seguirá siendo un importante importador de soja y quizás incremente en el futuro sus importaciones de cereales (maíz, sorgo y cebada), que demandan para su producción grandes extensiones de tierra y disponibilidad de agua, recursos que son relativamente escasos en su territorio.

En materia de productos agroindustriales con mayor valor agregado, China tiene aranceles altos y escalonados. Además, utilizan regularmente requisitos técnicos y sanitarios para impedir selectivamente la competencia extranjera. La necesidad de generar puestos de trabajo empuja a China a sustituir importaciones y a localizar en su territorio las actividades de procesamiento o con mayor valor agregado.

En materia industrial, nuestra presencia es sumamente modesta. La mayoría de las importaciones industriales al mercado chino las realizan empresas multinacionales que invirtieron en China, relocalizando e integrando parte de sus operaciones en una cadena de comercio intra-industrial transnacional. Esta estrategia no es de fácil implementación para la mayoría de nuestras empresas que no tienen el tamaño ni el capital suficiente para intentar dicha solución.

\section{Lineamientos PARA LA Política EXTerior}

La emergencia de China y Asia nos presentan oportunidades que no debemos desaprovechar. Se trata, en lo esencial, de acceder a nuevos mercados de exportación, atraer inversiones productivas y desarrollar relaciones políticas equilibradas y respetuosas sin penalizar las relaciones fructíferas que mantenemos con nuestros socios tradicionales ( nuestros vecinos 
sudamericanos, el resto de América Latina, Europa y los Estados Unidos).

Si hacemos las cosas bien, China podría llegar a representar alrededor del 10\%-12\% de nuestras exportaciones totales (versus $7,5 \%$ en la actualidad).

El camino más apropiado para incrementar nuestras exportaciones al mercado chino es atrayendo inversiones chinas a los sectores minero, petrolero y agrícola así como a la infraestructura relacionada a la logística de exportación (ferrocarriles, puertos y rutas).

En el campo minero existen varios grandes proyectos en oro, cobre, potasio y litio que podrían transformarse en importantes polos exportadores durante los próximos años. La inversión de grandes empresas mineras chinas en «joint ventures» con empresas estatales provinciales podrían sentar las bases para un desarrollo conjunto provechoso. El estado nacional debiera prestar su apoyo para que las provincias participen como accionistas minoritarios en dichos proyectos.

En el campo energético, la compra de las operaciones locales de Occidental Petroleum por Sinopec y la inversión de la empresa CNOOC en Bridas, así como el interés expresado por estas dos grandes petroleras de participar activamente en los procesos de exploración y desarrollo de Vaca Muerta y de nuestra extensa y poca explorada plataforma marítima, abren un campo significativo a la participación china en nuestra economía.

En el campo agroalimentario -con paciencia y perseverancia para negociar las restricciones sanitarias-, la Argentina tendría algún campo para ampliar sus exportaciones en carnes bovinas y avícolas, cueros, pescados congelados, cítricos, frutas en contra estación, leche en polvo, lana, tabaco y posiblemente quesos, vinos finos, maderas duras.

En el campo de las manufacturas también habría algunas oportunidades en los rubros de químicos orgánicos, plásticos, tubos de acero sin costura, productos farmacéuticos y veterinarios y maquinaria agrícola.

Pero debemos aprovechar la oportunidad que se nos presenta en el campo económico con una alta dosis de realismo: 1. China está fundamentalmente interesada en la Argentina como proveedora de alimentos, minerales y energía. 
China no pretende establecer relaciones privilegiadas con la Argentina sino diversificar sus fuentes de aprovisionamiento y mejorar las condiciones de compras respecto a sus proveedores habituales.

2. Siguiendo la lógica británica de fines del siglo XIX, China está dispuesta a invertir para producir y transportar con eficiencia las materias primas que desea importar. Durante los últimos años, las principales inversiones chinas anunciadas en petróleo (Sinopec y CNOOC), mineral de hierro (Sierra Grande), un puerto privado en Santa Fe (Noble) y los créditos otorgados para modernizar el ferrocarril Belgrano, confirman dichas preferencias.

3. Debemos atraer a grandes empresas chinas para que inviertan en nuestro país en proyectos de largo plazo que generen un flujo continuo de exportaciones. La inversión en activos fijos crea un interés compartido que asegura un acceso preferencial a los mercados, sobre todo en los momentos de dificultad. Nuestra experiencia histórica con Gran Bretaña es, en ese respecto, aleccionadora.

Para ello, debemos ofrecer estabilidad en las reglas del juego. Es esencial para desarrollar una relación sólida de largo plazo, un tratamiento equitativo, respetuoso y no discriminatorio

4. Desafortunadamente, China importa pocos de los productos con mayor valor agregado que nosotros exportamos. La concentración de nuestras exportaciones en materias primas es un dato duro de la realidad que tendremos que aceptar aunque no nos guste.

Para favorecer, en la medida de lo posible, el acceso de productos con mayor valor agregado al mercado chino tendremos que : (i) sortear las restricciones sanitarias y técnicas que son bastante generalizadas; (ii) invertir en China en plantas procesadoras de materias primas o de insumos industriales exportados desde nuestro país (como ya lo han hecho en una escala limitada empresas metalúrgicas, farmacéuticas y bodegas); (iii) convencer a empresas multinacionales con inversiones en nuestro país de integrarnos a su cadena de producción transnacional. El gobierno, en conjunto con el sector privado, debería promover en forma organizada todas estas iniciativas. 
5. La firma de un tratado de libre comercio bilateral con China no ofrece por el momento ventajas sustantivas para la Argentina. China firmó durante los últimos años tratados bilaterales de libre comercio con Chile, Perú y Costa Rica.

El acuerdo con Chile asegura el acceso de los productos chilenos tradicionales (cobre y mineral de hierro) al mercado chino, ofrece protección a las inversiones recíprocas y reafirma la apertura del mercado chileno para las manufacturas chinas (Chile concedió poco porque tiene de partida un nivel bajísimo de aranceles, salvo en los productos agropecuarios donde los chinos no compiten). Por su parte, las concesiones arancelarias que otorgó China le costaron poco porque, salvo en algunos productos puntuales (frutas, salmón y madera), tienen una capacidad competitiva muy acotada.

En el campo político, la inexistencia de potenciales conflictos estratégicos con China es un activo valioso que debemos preservar.

Como China es y será un importante socio económico y comercial durante las próximas décadas, no debemos entrometernos en sus problemas políticos internos ni asociarnos automáticamente a las críticas que algunos países occidentales hacen respecto al funcionamiento de su sociedad.

En el campo estratégico, debemos ser cautelosos y no dejarnos llevar por el entusiasmo de la novedad a establecer arreglos estratégicos o militares que pudieran, en el futuro, involucrarnos en potenciales conflictos.

Por ahora, el negocio de China con la Argentina son los negocios y no la geopolítica. Entre la Argentina y China prima una relación económica y parece poco probable que los chinos intervengan directamente en la política interna de nuestro país.

Probablemente los chinos se comporten más como los británicos que como los norteamericanos. Es improbable que haya un «Braden o Perón» en el horizonte, pero tendremos que acostumbrarnos al vigoroso lobby de los chinos en los temas económicos de su interés (como lo hicieron los británicos con los frigoríficos y los ferrocarriles durante la primera mitad del siglo XX). 
El surgimiento de China mejora directa, y sobre todo indirectamente, nuestro posicionamiento económico internacional, pero no reemplaza la hegemonía estratégica y militar de los Estados Unidos en nuestro continente durante las próximas décadas.

No repitamos el error de pensar que podemos ser neutrales en el caso de un conflicto estratégico importante. Ese error ya lo cometimos en 1943 con las consecuencias indeseadas que Carlos Escudé lucidamente analizó en sus trabajos.

Que nos guste o no, la hegemonía hemisférica norteamericana nos pone a resguardo de cualquier amenaza militar china en el futuro, pero también nos impone ciertas límites que debemos respetar.

La Argentina, que por historia, cultura y principios políticos es próxima a los aliados occidentales, debe mantener una sana distancia y prescindencia respecto de la política exterior china en todos los temas que involucren los intereses geopolíticos y militares de los Estados Unidos, Japón y los aliados occidentales.

Debemos ser sumamente escrupulosos en todos los temas relacionados con lo militar, en particular, la compra de armamento y el otorgamiento de bases militares o satelitales a China (que podrían tener un uso dual).

\section{Conclusiones}

El fortalecimiento de la relación entre la Argentina y China nos enfrenta a desafíos internos y externos. En lo interno, se trata de aprovechar este favorable «golpe de fortuna» para modernizar nuestra sociedad, transformando las ganancias que resultan de los aumentos de los volúmenes y precios de nuestras exportaciones, en más inversión, mejor educación, infraestructura y solidez institucional.

El desafío externo es el de aprovechar las consecuencias económicas sin vernos envueltos en innecesarios conflictos geopolíticos que pudieran aflorar en el futuro entre China y otras potencias, en particular con los Estados Unidos y sus aliados occidentales.

Los períodos, como el actual, donde ocurren grandes mutaciones en el orden mundial, representan a la vez una gran oportunidad y un desafío para países como la Argentina. 
Hay que comenzar por normalizar la agenda de temas pendientes. Se trata de recomponer el crédito público externo, restablecer relaciones comerciales previsibles con nuestros socios y arreglar la larga lista de conflictos mal gestionados con vecinos y otros países.

La agenda de fondo requiere decidir sobre el posicionamiento internacional del país en el largo plazo. La preeminencia de consideraciones de corto plazo durante los últimos años postergó la reflexión profunda y el país no tiene una estrategia clara y articulada -mucho menos consensuada- en materia de alianzas, relaciones económicas preferenciales y tácticas diplomáticas.

En mi opinión, debemos definir nuestra política exterior a partir de tres ejes complementarios: integración profunda económica y estratégica con Brasil, Chile, nuestros vecinos sudamericanos y el resto de América Latina; alianza estratégica y económica con Occidente (Estados Unidos y Europa) y una asociación comercial dinámica e intensa con China, la India, Indonesia, el resto de Asia y los países emergentes de África y Medio Oriente.

A nivel regional, debemos profundizar el relacionamiento político, económico y estratégico con nuestros vecinos, en particular con Brasil. Necesitamos avanzar en la integración regional completando el proyecto inconcluso de «Unión Aduanera» (un mercado único sin aduanas interiores).

Al nivel global, debemos relacionarnos más provechosamente en lo estratégico y económico con los Estados Unidos y con Europa, nuestros socios y aliados tradicionales. El paso más importante sería integrar al Mercosur a la «Zona de Libre Comercio Transatlántica», actualmente en negociación entre los Estados Unidos y la Unión Europea. ${ }^{7}$

Finalmente, debiéramos desarrollar una asociación comercial e inversora dinámica con China, la India y el vasto

Para profundizar el tema de la asociación con los Estados Unidos y Europa pueden consultar mis artículos en Foreign Affairs, Finding Allies In The Backyard (agosto 2001) y en International Politik, The EU -Southern Cone Link (diciembre 2001) donde propuse la incorporación del Mercosur a un proyecto de integración transatlántico, como el que se negocia en la actualidad entre Estados Unidos y la Unión Europea. 
universo de los países emergentes de Asia, Medio Oriente y África. Los dos pilares indispensables para concretar con éxito dicha asociación comercial e inversora son una estrecha cooperación entre los sectores público y privado y la puesta en marcha de una política de negociaciones comerciales perseverante y ambiciosa.

Felipe de la Balze

Secretario General del Consejo Argentino para

las Relaciones Internacionales (CARI) 